\title{
Ten-Year Results of Reconstruction for Rheumatoid Cervical Spine Lesions and Occurrence Factor of Subaxial Subluxation
}

\author{
Daisuke Kurogochi ${ }^{1}$, Jun Takahashi ${ }^{1}$, Masashi Uehara ${ }^{1}$, Shota Ikegami ${ }^{1}$, \\ Shugo Kuraishi ${ }^{1}$, Toshimasa Futatsugi ${ }^{1}$, Hiroki Oba ${ }^{1}$, Takashi Takizawa ${ }^{1}$, \\ Ryo Munakata ${ }^{1}$, Terue Hatakenaka ${ }^{2}$, Michihiko Koseki ${ }^{2}$, Hiroyuki Kato ${ }^{1}$ \\ ${ }^{1}$ Department of Orthopaedic Surgery, Shinshu University School of Medicine, Matsumoto, Japan \\ ${ }^{2}$ Faculty of Textile Science and Technology, Shinshu University, Ueda, Japan
}

Study Design: Retrospective chart review.

Purpose: This study evaluated long-term surgical outcomes of computer-assisted reconstruction using transarticular or cervical pedicle screws for cervical spine lesions caused by advanced rheumatoid arthritis (RA).

Overview of Literature: We routinely employ C1-C2 transarticular and cervical pedicle screw instrumentation to reconstruct advanced and unstable RA cervical lesions. However, few reports are available on the long-term results of surgical reconstruction for rheumatoid cervical disorders, particularly regarding cervical pedicle screw fixation.

Methods: Six subjects (all female) with RA cervical lesions who underwent atlantoaxial or occipitocervical fixation and were followed for at least 10 years were retrospectively studied. A frameless, stereotactic, optoelectronic, computed tomography-based image guidance system was used for correct screw placement. Variables including the Japanese Orthopaedic Association score, EuroOol, Ranawat value, and C2-C7 angle before and 2, 5, and 10 years after surgery were assessed along with the occurrence of subaxial subluxation (SAS).

Results: Mean age at initial surgery was $58.2 \pm 7$ years (range, 51-68 years), and mean follow-up period was $141 \pm 11$ months (range, 122-153 months). Lesions included atlantoaxial subluxation (AAS, $n=2$ ) and AAS+vertical subluxation ( $n=4)$. Mean C2-C7 lordotic angle before and 2,5 , and 10 years after surgery was $20.1^{\circ} \pm 6.1^{\circ}, 21.0^{\circ} \pm 4.0^{\circ}, 18.8^{\circ} \pm 4.7^{\circ}$, and $17.8^{\circ} \pm 5.3^{\circ}$, respectively. SAS did not occur in cases maintaining the $\mathrm{C} 2-\mathrm{C} 7$ lordotic angle. In two cases where the $\mathrm{C} 2-\mathrm{C} 7$ lordotic angle declined from 5 years postoperatively, SAS occurred at the C2-C3 level in one and at the C4-C5 level in the other, both of which required reoperation.

Conclusions: Patients with rheumatoid cervical lesions who undergo atlantoaxial or occipitocervical fixation using C1-C2 transarticular or pedicle screws carry a risk of SAS for up to 10 years postoperatively, which may require reoperation.

Keywords: Ten-year; Rheumatoid; Cervical; Subaxial subluxation

Received Dec 27, 2018; Revised Feb 5, 2019; Accepted Feb 12, 2019

Corresponding author: Jun Takahashi

Department of Orthopaedic Surgery, Shinshu University School of Medicine, 3-1-1 Asahi, Matsumoto, Nagano 390-8621, Japan

Tel: +81-263-37-2659, Fax: +81-263-35-8844, E-mail: jtaka@shinshu-u.ac.jp 


\section{Introduction}

Rheumatoid arthritis (RA) is a chronic inflammatory joint disease of unknown etiology that is characterized by erosive synovitis. Synovial inflammation can lead to joint erosion and deterioration of periarticular soft tissues, which are integral for joint stability. Damage to ligaments and joints causes various forms of instability [1,2]. Cervical spine involvement in patients with RA is a common complication that often results in anatomical deformities, particularly those of the upper cervical spine [3], with radiological cervical spine involvement being present in up to $86 \%$ of all patients with RA [4,5]. Isolated atlantoaxial subluxation (AAS) occurs in the early disease stages. With further progression, osseous joint destruction can lead to vertical subluxation (VS). However, while affliction of the middle and lower cervical spine can cause subaxial subluxation (SAS), neurological deficits may occur at any time [6]. In one study, the incidences of VS and SAS in RA were significantly increased during a 5-year follow-up period [7]. These disorders could result in severe symptoms, including occipital/neck pain, quadriplegia, and respiratory muscle paralysis. In such cases, $\mathrm{C} 1-\mathrm{C} 2$ transarticular screw fixation or occipitocervical fixation and neurological decompression may be indicated.

We have routinely used a computed tomography (CT)based computer navigation system for planning and screw insertion into the $\mathrm{C} 1-\mathrm{C} 2$ transarticular joint or cervical pedicles to avoid severe injury to neural and vascular structures. We had previously examined mid-term outcomes using this method and reported good clinical results 2 years after surgery that had somewhat decreased 5 years postoperatively [8]. However, long-term data (i.e., 10 years or more) for surgical reconstruction of rheumatoid cervical disorders have been scarce. This study therefore aimed to evaluate long-term surgical outcomes of computer-assisted surgical reconstruction for advanced RA cervical lesions, with particular focus on SAS development.

\section{Materials and Methods}

Between January 2004 and June 2006, nine consecutive patients underwent $\mathrm{C} 1-\mathrm{C} 2$ transarticular screw fixation or occipitocervical fixation using pedicle screws for RA cervical lesions (AAS or AAS+VS) at our Shinshu University Hospital. Among them, one patient died and two were lost to follow-up. The remaining six patients (all female; mean \pm standard deviation [SD] age, 58.2 \pm 7.14 years) with RA cervical lesions receiving transarticular or pedicle screw instrumentation and at least 10 years of followup were retrospectively enrolled. The follow-up rate was $66.7 \%$. Clinical profiles and surgical details of the subjects are shown in Table 1. A frameless, stereotactic, optoelectronic, CT-based image-guidance system (Stealth Station and Stealth Station TREONTM; Medtronic Sofamor Danek, Memphis, TN, USA) was used for correct screw placement. This study was carried out with prior approval from the institutional ethics committee of Shinshu University School of Medicine (approval no., 4126). Written informed consents were obtained.

The following surgical procedures were performed: C1-C2 transarticular screw fixation (Magerl and Brooks procedure, Trans Bone Screw; KiscoMedica, St. Priest, France) for patients with AAS and occipitocervical fusion using the RRS Loop Spinal System (Robert Leid, Tokyo, Japan) for patients with AAS+VS. C1-C2 transarticular screw fixation (Magerl and Brooks procedure) was selected for reducible AAS without VS. Occipitocervical fusion $+\mathrm{C} 1$ laminectomy was performed for irreducible AAS and cases with a Ranawat value $<13 \mathrm{~mm}$ or medullary compression on magnetic resonance imaging.

The Japanese Orthopaedic Association (JOA) score [9], Ranawat classification [10], and EuroQol (EQ-5D) utility weight [11] were adopted for the clinical evaluation of cervical disorders with RA before and 2, 5, and 10 years after surgery. The Ranawat classification system is defined as follows: class I, no neural deficit; class II, subjective weakness with hyperreflexia and dysesthesia; class IIIA, objective findings of paresis and long-tract signs with the possibility of ambulation; and class IIIB, quadriparesis with resultant inability to walk or feed oneself [10]. The EQ-5D questionnaire consists of five sections covering health domains regarding mobility, self-care, usual activity, pain, and anxiety/depression. Each domain is rated according to three levels of severity: no problems (1 point), some or moderate problems (2 points), and severe problems (3 points). Utility weights can then be attached to the EQ-5D health state provided by the questionnaire. These weights are incrementally arranged on a scale wherein full health and death are represented by scores of 1 and 0 , respectively. Some severe health states are given negative scores, indicating that the patient's relative levels of dysfunction as measured by the aforementioned parameters 


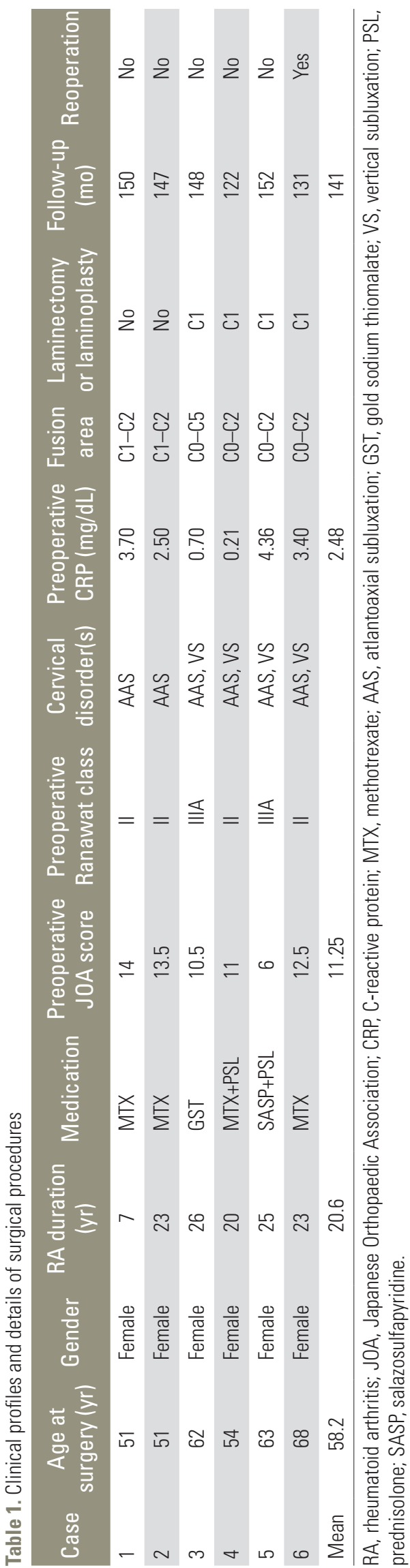

may be considered worse than death from a social perspective [11].

Plain radiographs of the cervical spine, including neutral, maximum flexion, and maximum extension lateral views, before and after surgery were evaluated. Radiologic evaluations were performed to determine Ranawat values and $\mathrm{C} 2-\mathrm{C} 7$ lordotic angles before and 2, 5, and 10 years after surgery [12]. Traditional methods of diagnosis relied on measurement of adjacent vertebrae, with SAS considered present when 3.5 to $4 \mathrm{~mm}$ of listhesis was found between vertebrae [13-15].

\section{Results}

The mean \pm SD follow-up period was $141.0 \pm 12$ months (range, 122-152 months), while the mean \pm SD preoperative duration for RA was 20.6 \pm 7 years (range, 7-25 months). Cervical spine disorders in this study included AAS $(n=2)$ and AAS+VS $(n=4)$ (Table 1$)$.

\section{Clinical assessment}

We had previously examined mid-term outcomes in this cohort and reported good clinical results 2 years after surgery that had diminished 5 years postoperatively. In the present, longer study, JOA scores and EQ-5D utility weights before and 2, 5, and 10 years after surgery were $11.2 \pm 1.2,13.6 \pm 0.3,11.0 \pm 0.7$, and $9.0 \pm 0.9$ and $0.48 \pm 0.06$, $0.69 \pm 0.10,0.55 \pm 0.02$, and $0.51 \pm 0.03$, respectively. Though JOA scores did not significantly improve 2 years post-surgery, no obvious deterioration was observed 5 years postsurgery. JOA scores 10 years after surgery tended to be lower than preoperative values (Fig. 1). An improvement in EQ-5D utility weights was observed 2 years post-surgery. EQ-5D utility weight scores 10 years after instrumentation were comparable to those before surgery (Fig. 1).

\section{Radiographic assessment}

Ranawat values before and 2, 5, and 10 years after surgery were $10.8 \pm 1.6,11.6 \pm 1.17,10.8 \pm 1.3$, and $11.0 \pm 1.4$, respectively, and were similar at all time points in our cohort (Fig. 1). In the four cases without SAS, the mean $\mathrm{C} 2-\mathrm{C} 7$ lordotic angle remained at $22.5^{\circ} 5$ to 10 years postoperatively (Fig. 2). SAS occurred at the $\mathrm{C} 2-\mathrm{C} 3$ level in one case (case $5)$ where the $\mathrm{C} 2-\mathrm{C} 7$ lordotic angle decreased from $20^{\circ}$ to $8^{\circ} 2$ to 5 years postoperatively but did not markedly re- 

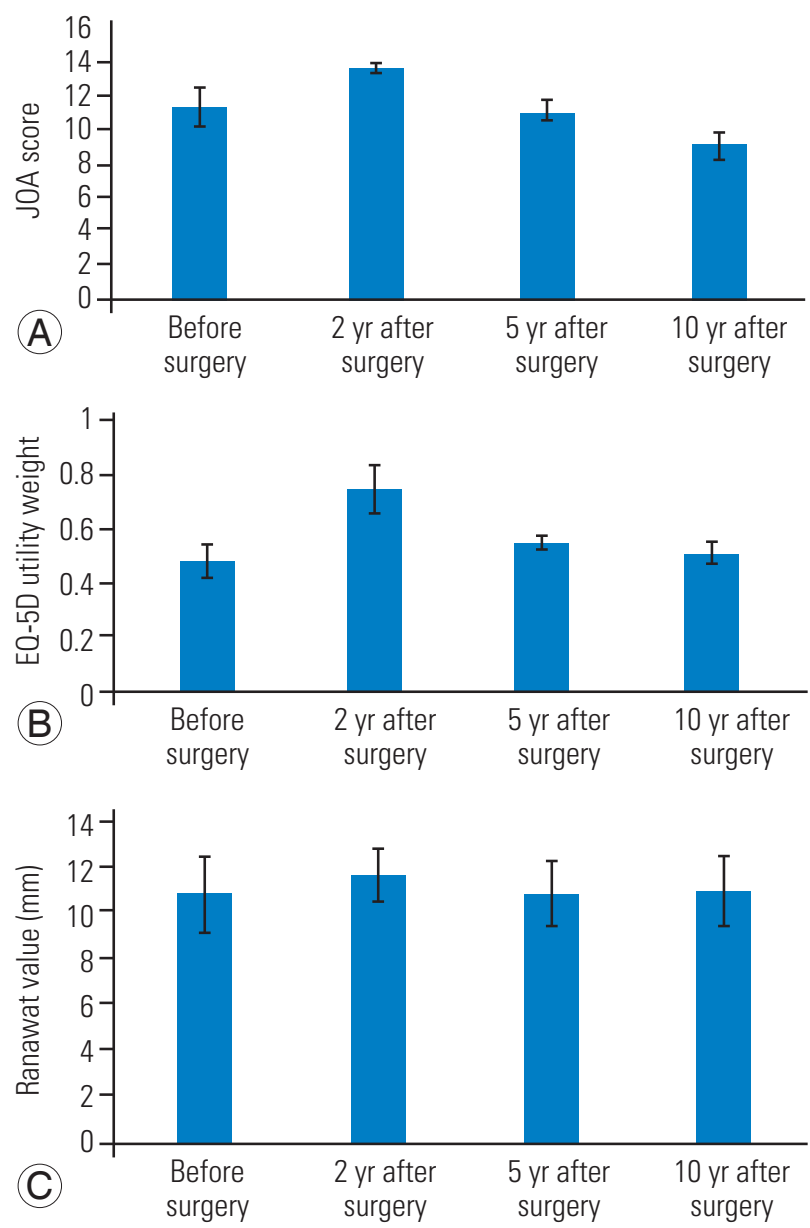

Fig. 1. Evaluation of JOA scores (A), EQ-5D utility weights (B), and Ranawat values (C). Error bars represent the mean \pm standard error of the mean. JOA, Japanese Orthopaedic Association; EQ-5D, Euro0ol.

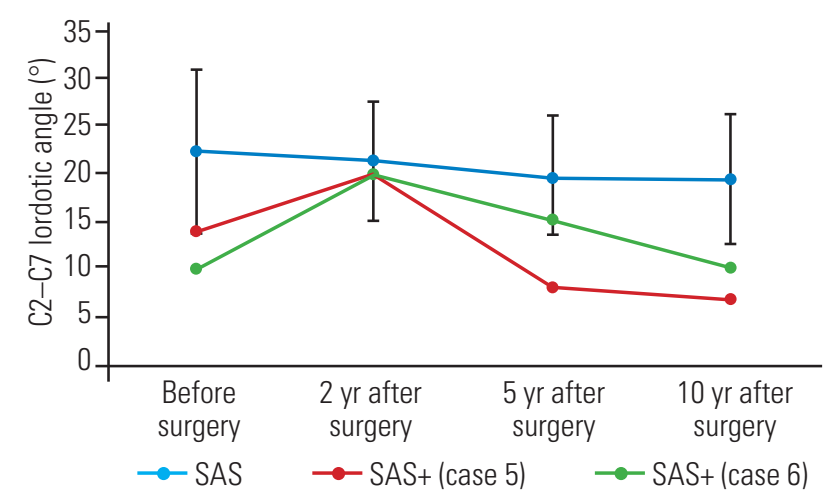

Fig. 2. Changes in the C2-C7 lordotic angle during the observation period. SAS, subaxial subluxation; SAS+, occurrence of SAS.

gress further (Fig. 2). In another case (case 6) where SAS occurred and reoperation was needed due to paralysis, the $\mathrm{C} 2-\mathrm{C} 7$ lordotic angle decreased from $15^{\circ}$ to $10^{\circ} 5$ to 10 years postoperatively (Fig. 2).

\section{Case presentations}

1) Case 1: a 51-year-old woman with AAS due to destructive RA

The preoperative JOA score and EQ-5D utility weight were 14 points and 0.631 , respectively. $\mathrm{C} 1-\mathrm{C} 2$ transarticular fixation was performed. The JOA score and EQ-5D utility weight 5 and 10 years after surgery were 10.5 points and 0.533 and 9 points and 0.533 , respectively. The $\mathrm{C} 2-\mathrm{C} 7$ lordotic angle was preserved, and no SAS had occurred 10 years after surgery (Fig. 3).

2) Case 3: a 62-year-old woman with AAS and VS due to destructive RA

The preoperative JOA score and EQ-5D utility weight were 11.5 points and 0.282 , respectively. Occipitocervical fixation (C0-C5) was carried out. The JOA score and EQ-5D utility weight 5 and 10 years after surgery were 13 points and 0.596 and 10.5 points and 0.533 , respectively. The C2-C7 lordotic angle was maintained, and no SAS had occurred 10 years postoperatively (Fig. 4).

3) Case 5: a 63-year-old woman with AAS and VS due to destructive RA

The preoperative JOA score and EQ-5D utility weight were 6 points and 0.419 , respectively. Occipitocervical fixation $(\mathrm{C} 0-\mathrm{C} 2)$ was performed. At 5 years after surgery, the JOA score and EQ-5D utility weight were 9 points and 0.587 , respectively. The $\mathrm{C} 2-\mathrm{C} 7$ lordotic angle had decreased 3 years earlier. At 10 years after surgery, the JOA score and EQ-5D utility weight were 9 points and 0.613, respectively. The $\mathrm{C} 2-\mathrm{C} 7$ lordotic angle had remained constant from 5 years postoperatively (Fig. 5). However, SAS occurred at the $\mathrm{C} 2-\mathrm{C} 3$ level with $3 \mathrm{~mm}$ of horizontal displacement on lateral flexion and extension radiography. Mild instability was noted [16].

4) Case 6: a 68-year-old woman with AAS and VS due to destructive RA

The preoperative JOA score and EQ-5D utility weight were 10.5 points and 0.37 , respectively. Occipitocervical fixation $(\mathrm{C} 0-\mathrm{C} 2)$ was carried out. At 5 years after surgery, the JOA score and EQ-5D utility weight were 11 points and 0.596 , respectively. The $\mathrm{C} 2-\mathrm{C} 7$ lordotic angle was lower than that at an earlier time point, and SAS had oc- 


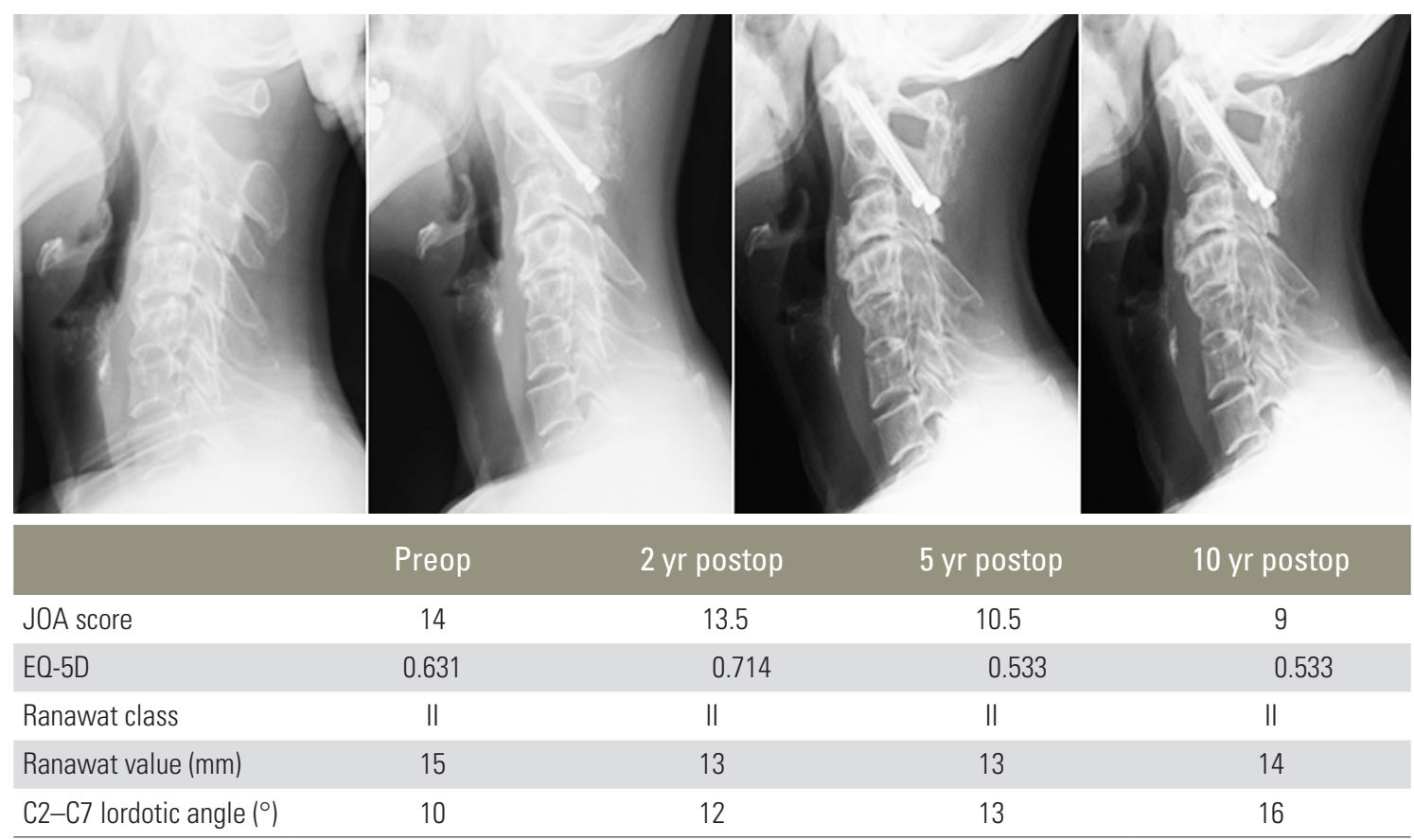

Fig. 3. Case 1: changes in radiographic results and parameters during the observation period. Preop, preoperative; Postop, postoperative; JOA, Japanese Orthopaedic Association; EQ-5D, EuroOol.

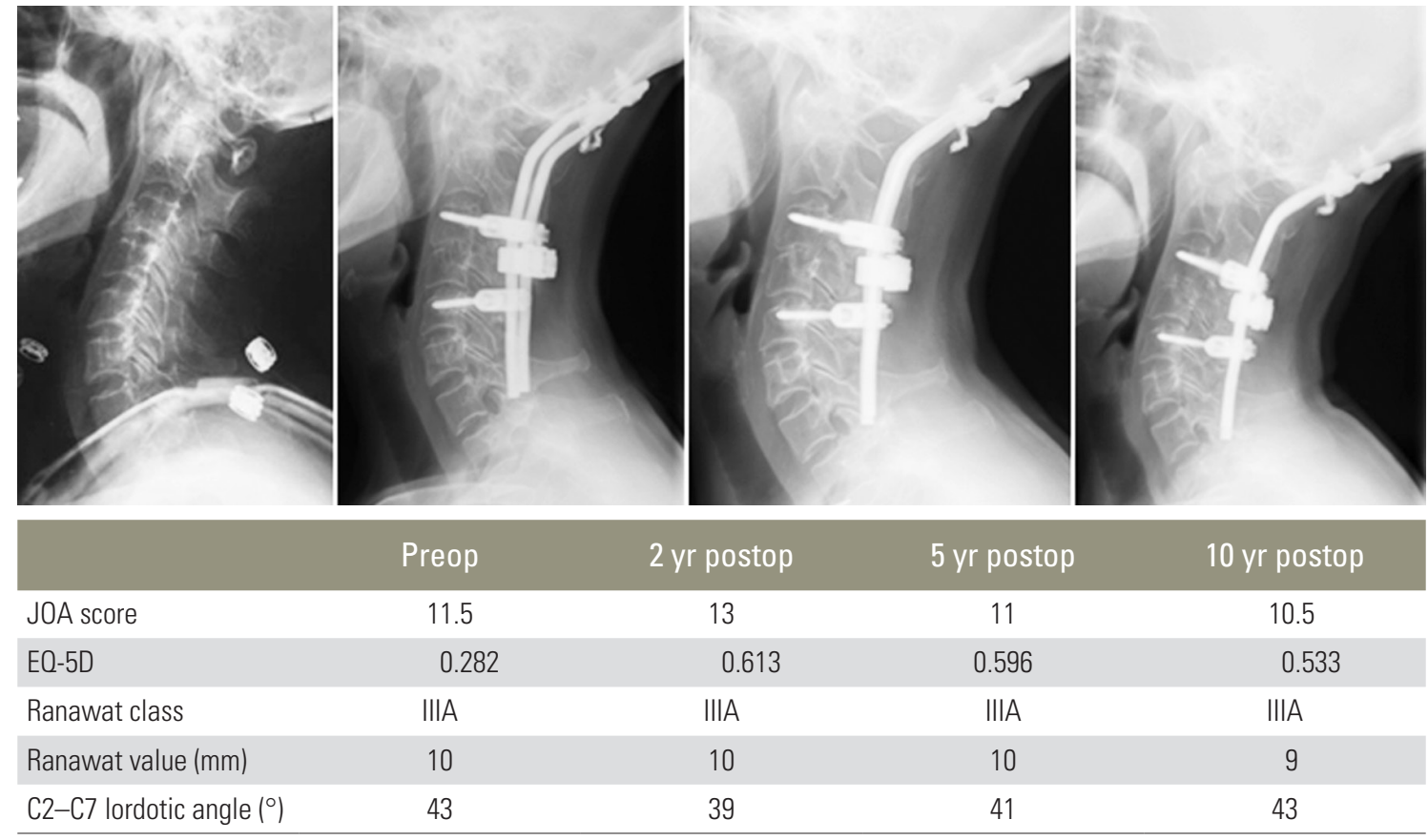

Fig. 4. Case 3: changes in radiographic results and parameters during the observation period. Preop, preoperative; Postop, postoperative; JOA, Japanese Orthopaedic Association; EQ-5D, EuroOol.

curred at the C5-C6 level. At 10 years after surgery, the JOA score and EQ-5D utility weight were 5 points and 0.33 , respectively. The $\mathrm{C} 2-\mathrm{C} 7$ lordotic angle was lower compared to that 5 years prior. SAS had also occurred at the C4-C5 level (Fig. 6), which caused instability and paralysis. Additional $\mathrm{C} 2-\mathrm{C} 7$ pedicle screw fixation and domino connection improved her neurological symptoms. 


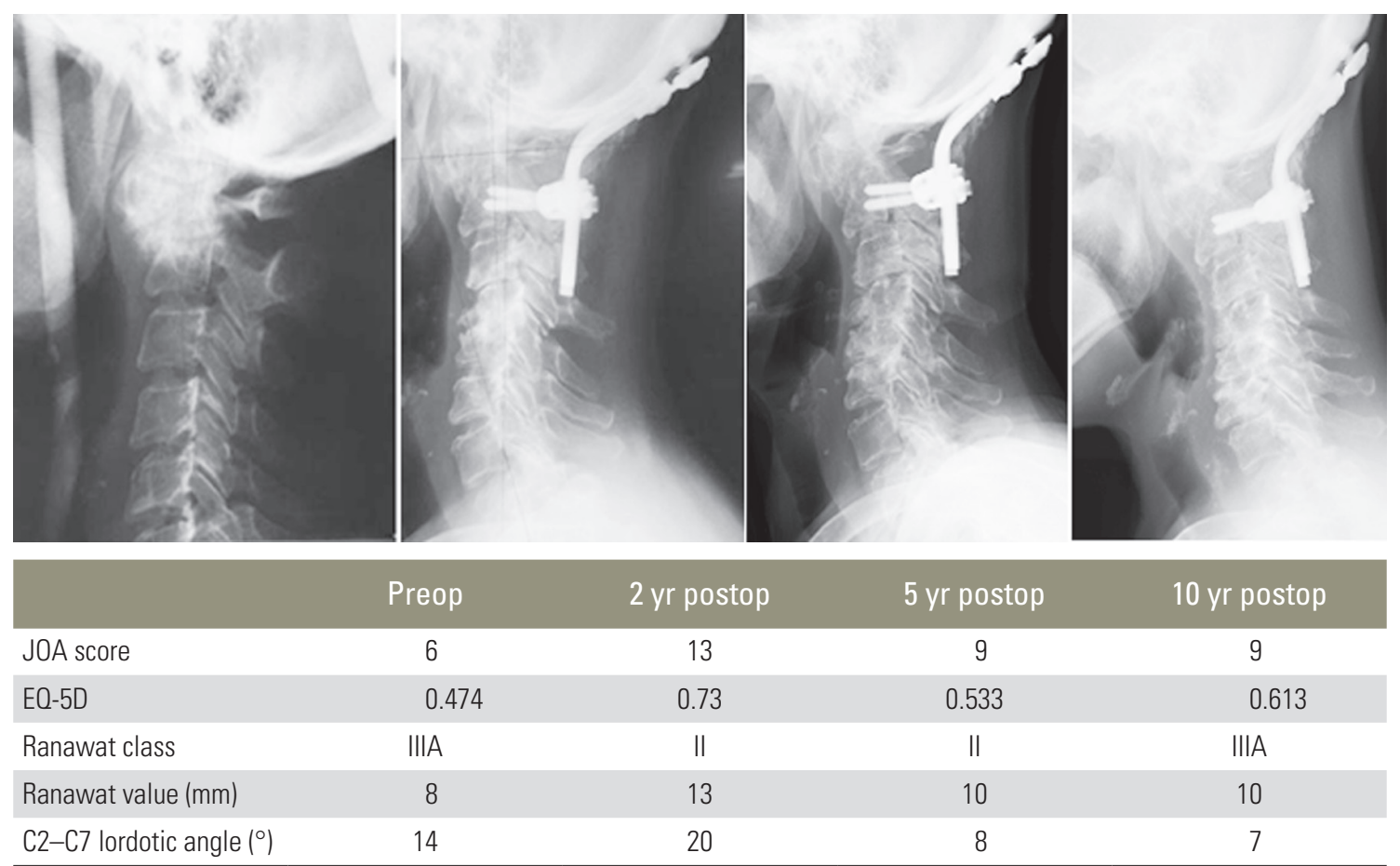

Fig. 5. Case 5: changes in radiographic results and parameters during the observation period. Preop, preoperative; Postop, postoperative; JOA, Japanese Orthopaedic Association; EQ-5D, Euro0ol.

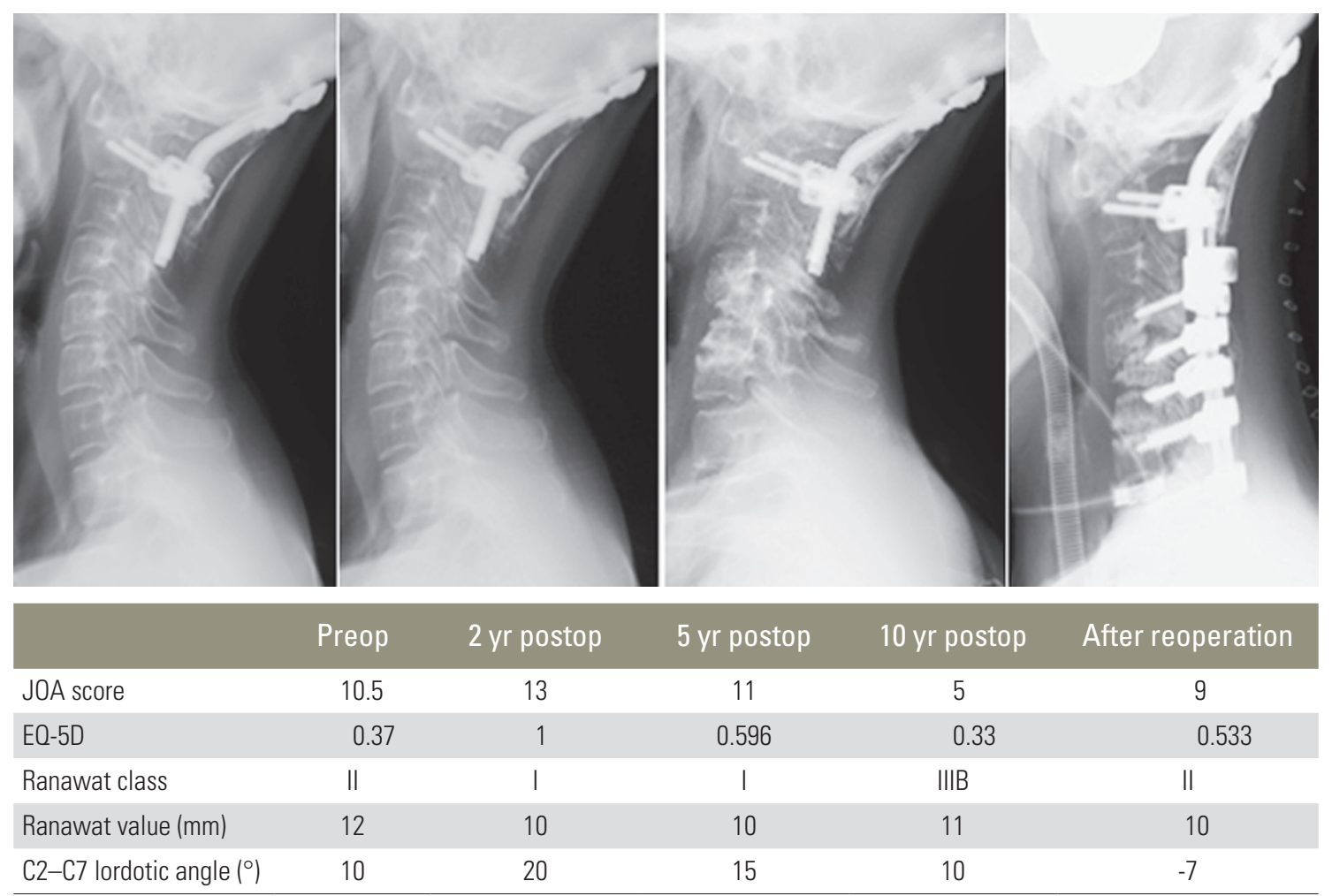

Fig. 6. Case 6: changes in radiographic results and parameters during the observation period. Preop, preoperative; Postop, postoperative; JOA, Japanese Orthopaedic Association; EQ-5D, Euro0ol. 


\section{Discussion}

This study revealed several key features regarding the long-term reconstruction results of RA cervical lesions. First, JOA scores had improved 2 years after surgery but gradually deteriorated during follow-up and tended to be worse than pre-surgery levels 10 years postoperatively. Second, although EQ-5D utility weights also improved 2 years after surgery and deteriorated during follow-up, scores 10 years post-surgery were generally better than those before treatment. Third, Ranawat values were maintained before and after surgery. Lastly, SAS and ensuing myelopathy developed in one case where the $\mathrm{C} 2-\mathrm{C} 7$ lordotic angle began decreasing 2 years postoperatively.

We have routinely employed $\mathrm{C} 1-\mathrm{C} 2$ transarticular and cervical pedicle screw instrumentation to reconstruct highly advanced and unstable RA cervical lesions. An earlier clinical assessment of mid-term outcomes using this method revealed favorable results 2 years after surgery that diminished 5 years post-surgery [8]. Considering the limited data on the longer-term results of surgical reconstruction for rheumatoid cervical disorders, this study sought to characterize the 10-year surgical outcomes of computer-assisted cervical reconstruction.

Our findings showed that SAS did not occur in patients who maintained the $\mathrm{C} 2-\mathrm{C} 7$ lordotic angle 5 years after surgery. In case 5 , the $\mathrm{C} 2-\mathrm{C} 7$ lordotic angle decreased 2 to 5 years after surgery but remained constant thereafter. At 10 years after surgery, SAS with mild instability had occurred at the C2-C3 level [16]. However, no paralysis and reoperation were needed, although additional surgery may be necessary in the future. In case 6 , the $\mathrm{C} 2-\mathrm{C} 7$ lordotic angle decreased steadily 2 to 10 years postoperatively, while SAS occurred at both the C4-C5 and C5C6 levels. Accordingly, C2-C7 pedicle screw fixation and domino connection were performed due to paralysis from instability at the C4-C5 level.

Clarke et al. [17] suggested that the high occurrence rate of SAS after surgery was probably due to mechanical stress caused by changes in cervical alignment, whereas the natural history of SAS at least partially originates from inflammatory processes. However, only a few studies on the long-term risk factors of SAS have been available. Accordingly, Ishii et al. [18] revealed that the average preoperative $\mathrm{C} 2-\mathrm{C} 7$ angle in a SAS group decreased significantly after surgery and that the postoperative C2-C7 angle in the SAS group was significantly smaller than that of non-SAS patients. Similarly, the present study showed that cases with instability at the $\mathrm{C} 2-\mathrm{C} 3$ level and SAS had a smaller postoperative $\mathrm{C} 2-\mathrm{C} 7$ lordotic angle than cases without SAS. Based on our 10-year findings, the occurrence of SAS requiring reoperation is possible in cases with persistent $\mathrm{C} 2-\mathrm{C} 7$ lordotic angle decrease.

The limitations of this study include the lack of a control group, small sample size, various pathologies, and retrospective design. Notwithstanding, the present investigation provides important long-term evidence on transarticular or cervical pedicle screw fixation for rheumatoid cervical disorders.

\section{Conclusions}

Subjects with rheumatoid cervical lesions who undergo C1-C2 transarticular or occipitocervical fixation using pedicle screws may carry a risk of SAS within the 10 years following surgery, which may require reoperation.

\section{Conflict of Interest}

No potential conflict of interest relevant to this article was reported.

\section{References}

1. Halla JT, Fallahi S. Cervical discovertebral destruction, subaxial subluxation, and myelopathy in a patient with rheumatoid arthritis. Arthritis Rheum 1981;24:944-7.

2. McConkey B. Rheumatoid cervical myelopathy. $\mathrm{Br}$ Med J (Clin Res Ed) 1982;284:1731-2.

3. Halla JT, Hardin JG, Vitek J, Alarcon GS. Involvement of the cervical spine in rheumatoid arthritis. Arthritis Rheum 1989;32:652-9.

4. Pellicci PM, Ranawat CS, Tsairis P, Bryan WJ. A prospective study of the progression of rheumatoid arthritis of the cervical spine. J Bone Joint Surg Am 1981;63:342-50.

5. Smith PH, Benn RT, Sharp J. Natural history of rheumatoid cervical luxations. Ann Rheum Dis 1972;31:431-9.

6. Kothe R, Wiesner L, Ruther W. Rheumatoid arthritis of the cervical spine: current concepts for diagnosis and therapy. Orthopade 2002;31:1114-22.

7. Yurube T, Sumi M, Nishida K, et al. Progression of 
cervical spine instabilities in rheumatoid arthritis: a prospective cohort study of outpatients over 5 years. Spine (Phila Pa 1976) 2011;36:647-53.

8. Uehara M, Takahashi J, Ogihara N, et al. Mid-term results of computer-assisted cervical reconstruction for rheumatoid cervical spines. J Orthop Sci 2013;18:916-25.

9. Japanese Orthopaedic Association. Scoring system for cervical myelopathy. J Jpn Orthop Assoc 1994;68:490-503.

10. Ranawat CS, O'Leary P, Pellicci P, Tsairis P, Marchisello P, Dorr L. Cervical spine fusion in rheumatoid arthritis. J Bone Joint Surg Am 1979;61:1003-10.

11. EuroQol Group. EuroQol: a new facility for the measurement of health-related quality of life. Health Policy 1990;16:199-208.

12. Matsumoto M, Chiba K, Nakamura M, Ogawa Y, Toyama Y, Ogawa J. Impact of interlaminar graft materials on the fusion status in atlantoaxial transarticular screw fixation. J Neurosurg Spine 2005;2:23-6.

13. Nguyen HV, Ludwig SC, Silber J, et al. Rheumatoid arthritis of the cervical spine. Spine J 2004;4:329-34.

14. Wasserman BR, Moskovich R, Razi AE. Rheumatoid arthritis of the cervical spine: clinical considerations. Bull NYU Hosp Jt Dis 2011;69:136-48.

15. Mallory GW, Halasz SR, Clarke MJ. Advances in the treatment of cervical rheumatoid: less surgery and less morbidity. World J Orthop 2014;5:292-303.

16. White AA 3rd, Johnson RM, Panjabi MM, Southwick WO. Biomechanical analysis of clinical stability in the cervical spine. Clin Orthop Relat Res 1975;(109):8596.

17. Clarke MJ, Cohen-Gadol AA, Ebersold MJ, Cabanela ME. Long-term incidence of subaxial cervical spine instability following cervical arthrodesis surgery in patients with rheumatoid arthritis. Surg Neurol 2006;66:136-40.

18. Ishii K, Matsumoto M, Takahashi $Y$, et al. Risk factors for development of subaxial subluxations following atlantoaxial arthrodesis for atlantoaxial subluxations in rheumatoid arthritis. Spine (Phila Pa 1976) 2010;35:1551-5. 